\title{
OPTIMISASI PEMBAGIAN TUGAS KARYAWAN MENGGUNAKAN METODE HUNGARIAN
}

\author{
Marline Paendong ${ }^{1}$, Jantje D. Prang ${ }^{1)}$ \\ ${ }^{1)}$ Program Studi Matematika FMIPA Universitas SamRatulangi Manado, 95115 \\ email: marline_paendong@yahoo.com
}

\begin{abstract}
ABSTRAK
Hal penting yang perlu dipertimbangkan dalam penugasan karyawan pada "Lia Fashion Komo Luar" adalah bagaimana kondisi penugasan agar kelebihan biaya produksi minimum sedangkan pada "Man Taylor" adalah bagaimana kondisi penugasan agar waktu produksi minimum. Dengan menggunakan metode Hungarian diperoleh hasil sebagai berikut: penugasan karyawan pada "Lia Fashion Komo Luar" agar kelebihan biaya produksi minimum adalah karyawan A ditugaskan menjahit seragam pramuka putri, karyawan B ditugaskan menjahit seragam SMA putri, dan karyawan C menjahit baju pegawai sedangkan pada "Man Taylor" agar waktu produksi minimum adalah karyawan A ditugaskan menjahit baju kebaya, karyawan $\mathrm{C}$ ditugaskan menjahit rok kebaya, karyawan D ditugaskan menjahit celana panjang, karyawan E ditugaskan menjahit rok pendek, karyawan F ditugaskan mejahit pakaian dinas harian (PDH), dan karyawan $\mathrm{G}$ ditugaskan menjahit baju kemeja.
\end{abstract}

Kata kunci: metode Hungarian, penugasan

\section{OPTIMIZATION OF DISTRIBUTION WORKER ASSIGNMENT USING HUNGARIAN METHOD}

\begin{abstract}
The Important point to be observe the worker assignment on "Lia Fashion Komo Luar" is how to condition of the assignment for minimum production cost advantages. While in "Man Taylor" is how the condition of the assignment for minimum production time. To simplify the assignment of these worker, there is a operation research method is the Assignment Problem using the Hungarian method. Assignment Problem is one case in the business world relating to the optimal assignment in which the number of worker equal to number of tasks to be done. Hungarian method is one technique for solving assignment problem consider the observation and problem formulation analysis afterwords by modifying the assignment table to the matrix of effectiveness in order to obtain optimal conditions. The results obtained by assignment of the right worker on the "Lia Fashion Komo Luar" for a minimum production cost advantage the worker A was assigned to sew scout uniform girls, worker B was assigned to sew school uniform girls, and worker $\mathrm{C}$ was assigned to sew officer clothes. While in "Man Taylor" for minimum production time the worker A was asiigned to sew kebaya clothes, worker $C$ was assigned to sew kebaya skirt, worker D was assigned to sew trousers, worker $\mathrm{E}$ was assigned to sew short dress, worker $\mathrm{F}$ was assigned to sew PDH clothes, and worker $G$ was assigned to sew shirt clothes.
\end{abstract}

Keywords: Hungarian method, assignment

\section{PENDAHULUAN}

\section{Latar Belakang}

Dewasa ini banyak usaha yang memproduksi barang dan jasa. Produk yang dihasilkan harus mampu menyaingi produk lain. Sehingga, perusahaan harus pandai mengelola aspek produksi dan menempatkan tenaga kerjanya secara tepat. Masalah penugasan (assignment problem) merupakan kasus yang sering ditemui dalam penanganan tenaga kerja. Salah satu metode yang digunakan untuk masalah penugasan optimal adalah metode Hungarian (Taha, 1996). 
Oleh sebab itu, dalam kesempatan ini penulis membahas "Optimasi Masalah Penugasan Menggunakan Metode Hungarian (Studi Kasus: Karyawan Lia Fashion Komo Luar dan Man Taylor). Untuk memfokuskan pemecahan masalah dan mempertegas lingkup penelitian, maka ditetapkan batasanbatasan yaitu:

1. ada kasus "Lia Fashion Komo Luar" jumlah karyawan sama dengan jumlah pekerjaan $(m=n)$. Sehingga penulis menggunakan sistem produksi kedua. Untuk biaya produksi yang digunakan dalam analisis adalah kelebihan nilai Cost ( biaya yang sudah melebihi biaya produksi yang telah ditetapkan).

2. Pada kasus "Man Taylor" jumlah karyawannya lebih banyak dibandingkan dengan jumlah pekerjaan yang akan diselesaikan dimana $(m \neq n)$.
Komo Luar" agar total kelebihan biaya produksi dapat diminimumkan.

2. Untuk mencari kondisi optimal penugasan karyawan pada "Man Taylor" agar total waktu penyelesaian pekerjaan dapat diminimumkan.

\section{TINJAUAN PUSTAKA}

\section{Masalah Penugasan}

Masalah penugasan (assignment problem) adalah suatu masalah mengenai pengaturan objek untuk melaksanakan tugas, dengan tujuan meminimalkan biaya, waktu, jarak, dan sebagainya ataupun memaksimalkan keuntungan yang salah satu penyelesaiannya menggunakan metode Hungarian ( Soemartojo, 1997 ).

Sehingga dapat digambarkan seperti pada Gambar 1.

\section{Tujuan Penelitian}

1. Untuk mencari kondisi optimal penugasan karyawan pada "Lia Fashion

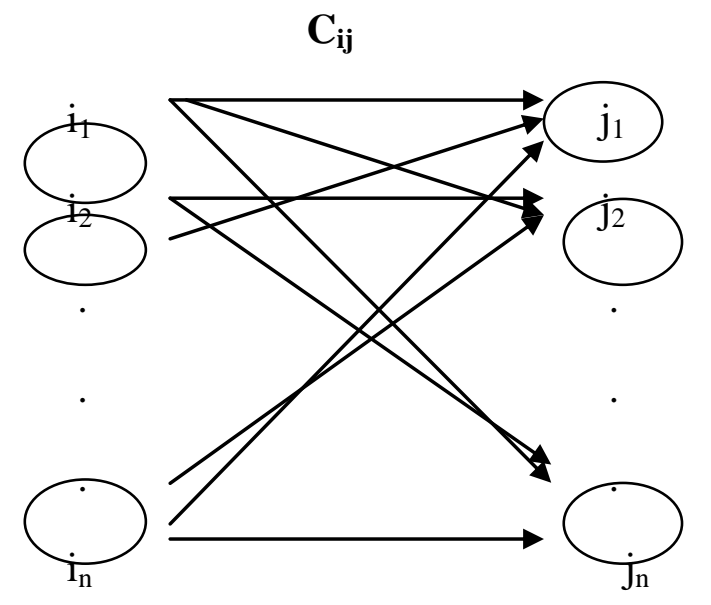

Keterangan: $m=\mathrm{i}_{1}, \mathrm{i}_{2, \ldots}, \mathrm{i}_{\mathrm{n}}$ dan $n=\mathrm{j}_{1}, \mathrm{j}_{2}, \ldots \mathrm{j}_{\mathrm{n}}$

Gambar 1. Proses pembentukan nilai penugasan

Secara matematis masalah penugasan dapat dinyatakan dalam bentuk variabel keputusan $x_{i j}$ yaitu:

$x_{i j}=1$,apabila objek i ditugaskan untuk tugas $\mathrm{j}$

$x_{i j}=0$, apabila objek i tidak ditugaskan untuk tugas $\mathrm{j}$

Secara mendetail model untuk masalah penugasan dapat ditulis :
Meminimumkan $Z=\sum_{i=1}^{m} \sum_{j=1}^{n} c_{i j} x_{i j}$

$Z=c_{11} x_{11}+c_{22} x_{22}+\ldots+c_{m n} x_{m n}$

Dengan kendala:

$\sum_{i=1}^{m} x_{i j}=1$ untuk $\mathrm{j}=1,2,3, \ldots . ., \mathrm{n}$ 
$\sum_{j=1}^{n} x_{i j}=1$ untuk $\mathrm{i}=1,2, \ldots, m$

$x_{i j} \geq 0$ untuk semua $\mathrm{i}$ dan $\mathrm{j}$

Dimana:

$\mathrm{Z}=$ Fungsi tujuan; $x_{i j}=$ Variabel keputusan;

$c_{i j}=$ Nilai konstribusi objek i terhadap tugas $\mathrm{j}$;

$m=$ Jumlah objek (individu atau sumber daya);

$n=$ Jumlah tugas/pekerjaan yang akan diselesaikan; i = Karyawan; j =Tugas/Pekerjaan Agustini dan Rahmadi (2004) menjelaskan bahwa masalah penugasan dalam keadaan tertentu akan mengalami cacah penugasan, dimana jumlah $m \neq n$. Namun dapat diatasi dengan menambahkan dummy worker atau dummy Job.

\section{Metode Hungarian}

Prawisentono (2005), mengungkapkan metode Hungarian adalah metode yang memodifikasi baris dan kolom dalam matriks efektifitas sampai muncul sebuah komponen nol tunggal dalam setiap baris atau kolom yang dapat dipilih sebagai alokasi penugasan. Semua alokasi penugasan yang dibuat adalah alokasi yang optimal, dan saat diterapkan pada matriks efektifitas awal, maka akan memberikan hasil penugasan yang paling minimum.

Taha (1996) memaparkan syarat-syarat metode Hungarian yaitu:

1. Jumlah i harus sama dengan jumlah j yang harus diselesaikan.

2. Setiap sumber hanya mengerjakan satu tugas.

3. Apabila jumlah sumber tidak sama dengan jumlah tugas atau sebaliknya, maka ditambahkan variabel dummy woker atau dummy job.

4. Terdapat dua permasalahan yang diselesaikan yaitu meminimumkan kerugian (biaya, waktu, jarak dan sebagainya) atau memaksimumkan keuntungan.

Masalah ini dapat dijelaskan dalam bentuk matriks opportunity cost $(m=n)$ dengan ukuran matriks $m \mathrm{x} n$. Definisi matriks biaya (cost matrix) yaitu: $c_{i j}=\left[\begin{array}{cccc}c_{11} & c_{12} & \ldots & c_{1 n} \\ c_{21} & c_{22} & \ldots & c_{2 n} \\ \ldots & \ldots & \ldots & \ldots \\ c_{m 1} & c_{m 2} & \ldots & c_{m n}\end{array}\right]$

Sedangkan matriks penugasan yaitu :

$$
x_{i j}=\left[\begin{array}{cccc}
x_{11} & x_{12} & \ldots & x_{1 n} \\
x_{21} & x_{22} & \ldots & x_{2 n} \\
\ldots & \ldots & \ldots & \ldots \\
x_{m 1} & x_{m 2} & \ldots & x_{m n}
\end{array}\right]
$$

Adapun langkah-langkah penyelesaian metode Hungarian adalah:

1. Memodifikasi tabel penugasan ke dalam matriks efektifitas. Dimana matriks ini dibentuk untuk memudahkan dalam proses penyelesaian setiap langkah metode yang telah dilakukan.

2. Memilih nilai terkecil dari setiap baris, lalu dilakukan operasi pengurangan dari tiap nilai di baris tersebut dengan bilangan terkecil yang telah dipilih. Dengan demikian, dapat dipastikan bahwa ada minimal satu buah elemen di tiap baris matriks yang bernilai nol dan tidak ada elemen dengan nilai negatif.

3. Melakukan pengurangan kolom jika terdapat kolom yang belum memiliki elemen 0 yaitu memilih nilai terkecil dari kolom, lalu dilakukan operasi pengurangan dari tiap nilai kolom dengan bilangan terkecil yang telah dipilih. Dengan demikian, dapat dipastikan bahwa ada minimal satu buah elemen di tiap baris dan tiap kolom matriks yang bernilai nol dan tidak ada elemen dengan nilai negatif.

4. Membentuk penugasan optimum yaitu dengan menarik sejumlah garis horisontal dan atau vertikal yang melewati seluruh sel yang bernilai 0. Jika jumlah garis sama dengan jumlah baris/ kolom maka penugasan telah optimal. Jika tidak maka harus direvisi.

5. Melakukan revisi tabel dengan memilih nilai terkecil yang tidak dilewati garis lalu kurangkan dengan semua nilai yang tidak dilewati garis. Kemudian ditambahkan pada angka yang terdapat pada persilangan garis. Kembali ke langkah 5.

6. Penugasan ditempatkan pada sel yang bernilai 0 . Dimana Tiap angka 0 diganti dengan angka 1 tetapi tiap kolom dan 
baris hanya memiliki satu angka 1 sebagai penugasan.

7. Menghitung total nilai dari solusi yang diperoleh berdasarkan elemen dari matriks awal yang belum direduksi nilainya sehingga diperoleh total nilai optimum.

\section{METODOLOGI PENELITIAN}

\section{Objek Penelitian}

Dalam penulisan ini menggunakan objek penelitian yaitu karyawan pada usaha "Lia Fashion Komo Luar" dan karyawan "Man Taylor" yang dimulai pada bulan Januari sampai Februari 2011.

\section{Metode Pengumpulan Data}

Data-data yang digunakan adalah data sekunder yaitu data yang sudah tercatat dan diolah tempat usaha. Selain itu diperlukan data penunjang yang diperoleh dari hasil wawancara dan observasi.

\section{Analisis Data}

Penelitian ini menggunakan analisis kuantitatif yaitu menganalisis data kelebihan biaya produksi setiap karyawan pada "Lia Fashion Komo Luar" dan waktu penyelesaian pekerjaan pada "Man Taylor" menggunakan metode Hungarian untuk meminimalkan kelebihan total biaya produksi dan waktu penyelesaian pekerjaan.

Tabel 1. Pembentukan biaya penugasan "Lia Fashion Komo Luar"

\begin{tabular}{|c|l|l|c|}
\hline \multirow{2}{*}{$\begin{array}{c}\text { Karyawan } \\
\text { (i) }\end{array}$} & \multicolumn{3}{|c|}{ Pekerjaan (j) } \\
\cline { 2 - 4 } & $\begin{array}{c}\text { Seragam } \\
\text { SMA } \\
\text { putri (I) }\end{array}$ & $\begin{array}{c}\text { Seragam } \\
\text { pramuka } \\
\text { putri (II) }\end{array}$ & $\begin{array}{c}\text { Baju } \\
\text { Pegawai } \\
\text { (III) }\end{array}$ \\
\hline $\mathrm{A}$ & $\mathrm{C}_{11}$ & $\mathrm{C}_{12}$ & $\mathrm{C}_{13}$ \\
\hline $\mathrm{B}$ & $\mathrm{C}_{21}$ & $\mathrm{C}_{22}$ & $\mathrm{C}_{23}$ \\
\hline $\mathrm{C}$ & $\mathrm{C}_{31}$ & $\mathrm{C}_{32}$ & $\mathrm{C}_{33}$ \\
\hline
\end{tabular}

Kuantitas yang diperoleh yaitu cij = kelebihan biaya produksi yang digunakan karyawan i kepada pekerjaan $\mathrm{j}$ dimana $\mathrm{c}_{\mathrm{ij}}=$ $\mathrm{c}_{11}, \mathrm{c}_{12, \ldots}, \mathrm{c}_{33}$. untuk i terdapat 3 karyawan dan $\mathrm{j}$ terdapat 3 pekerjaan.

Kuantitas yang diperoleh yaitu $c_{i j}=$ waktu yang digunakan karyawan i untuk menyelesaikan pekerjaan $\mathrm{j}$ dimana $\mathrm{c}_{\mathrm{ij}}=$ $\mathrm{c}_{11}, \mathrm{c}_{12, \ldots}, \mathrm{c}_{77}$. untuk i terdapat 7 karyawan dan $\mathrm{j}$ terdapat 6 pekerjaan. Sedangkan D adalah penambahan dummy job sehingga i menjadi 7 pekerjaan. Setelah data terpresentasi dalam bentuk tabel penugasan, langsung diselesaikan dengan menggunakan metode Hungarian dengan langkah sebagai berikut:

1. Nilai $c_{i j}$ pada tabel penugasan diubah ke dalam bentuk matriks efektifitas.

2. Melakukan pengurangan baris dengan nilai terkecil setiap baris.

3. Melakukan pengurangan kolom dengan nilai terkecil setiap kolom.

4. Membentuk penugasan optimum.

5. Melakukan revisi tabel.

6. Menentukan posisi penugasan.

7. Menghitung total nilai optimum.

\section{HASIL DAN PEMBAHASAN}

\section{Data dan Profil Objek Penelitian}

"Lia Fashion Komo Luar"

"Lia Fashion Komo Luar" merupakan usaha konveksi yang memproduksi dan mendistribusikan berbagai hasil jahitan dengan 3 sistem produksi yaitu sistem produksi pertama, kedua, dan ketiga.

Sistem produksi pertama yaitu jahitan yang diproduksi tiap hari seperti baju olahraga, bendera, baju sekolah SD sampai SMA, rok dan celana sekolah SD sampai SMA serta baju, celana, dan rok pramuka yang ditangani oleh 11 karyawan.

Sistem produksi kedua yaitu jahitan yang diproduksi 1 kali dalam seminggu dengan batasan 60 lembar produksi jahitan dalam 1 hari untuk tiap jenis jahitan terdiri dari seragam putri SMA, seragam pramuka putri dan baju pegawai yang ditangani oleh 3 karyawan.

Ketiga, sistem produksi berbagai jenis pakaian jadi dan perlengkapan rumah tangga ditangani oleh 5 orang dan diproduksi sesuai permintaan konsumen. Dalam usaha ini tidak ditemukan penempatan karyawan secara tepat dimana setiap karyawan bekerja berdasarkan pekerjaan yang menanti untuk ditangani tanpa adanya pembagian tugas secara jelas yang mengakibatkan kurang optimalnya biaya produksi. Dalam sistem produksi kedua, karakteristiknya sesuai dengan masalah penugasan, dalam hal ini jumlah karyawan sama dengan jumlah pekerjaan, dimana $m=n$. 
Tabel 2. Kelebihan biaya produksi penugasan keseluruhan

\begin{tabular}{|c|c|c|c|}
\hline \multirow{2}{*}{} & \multicolumn{3}{|l|}{ Jenis Pekerjaan Jahitan } \\
\cline { 2 - 4 } & $\begin{array}{c}\text { Srg SMA } \\
\text { Putri }\end{array}$ & $\begin{array}{c}\text { Srg Pramka } \\
\text { Putri }\end{array}$ & Baju Pegawai \\
\hline A & Rp 2.000 & Rp 3.000 & Rp 25.000 \\
\hline B & Rp 2.000 & Rp 16.000 & Rp 50.000 \\
\hline C & Rp 3.000 & Rp 2.000 & Rp 8.000 \\
\hline
\end{tabular}

\section{Data dan Profil Objek Penelitian "Man Taylor"}

"Man Taylor" adalah usaha jahitan yang melayani permintaan jahitan pakaian jadi. Dimana produksinya terdiri dari pekerjaan untuk menjahit baju kemeja, rok pendek, baju PDH, celana panjang, kebaya, dan rok kebaya yang ditangani oleh 7 karyawan. Pembagian tugas karyawannya telah ditetapkan, namun terdapat 1 karyawan yang tidak memiliki penempatan secara jelas sehingga penugasan dapat dianalisis ulang berdasarkan waktu penyelesaian pekerjaan tiap karyawan.

Tabel 3. Waktu penugasan yang dibutuhkan setiap karyawan dalam menyelesaikan setiap pekerjaan dalam satuan jam:menit:detik

\begin{tabular}{|c|c|c|c|c|c|c|c|}
\hline \multirow{2}{*}{$\begin{array}{c}\text { Karyawan } \\
\text { (i) }\end{array}$} & \multicolumn{7}{|c|}{ Pekerjaan (j) } \\
\cline { 2 - 9 } & (I) & (II) & (III) & (IV) & (V) & (VI) & D \\
\hline A & $02: 24: 46$ & $00: 47: 18$ & $01: 38: 17$ & $01: 34: 21$ & $02: 06: 17$ & $00: 43: 47$ & 0 \\
\hline B & $02: 18: 55$ & $00: 47: 56$ & $01: 42: 59$ & $01: 24: 36$ & $02: 22: 54$ & $00: 44: 55$ & 0 \\
\hline C & $02: 15: 18$ & $00: 47: 49$ & $01: 52: 31$ & $01: 15: 17$ & $02: 15: 35$ & $00: 42: 33$ & 0 \\
\hline D & $02: 23: 54$ & $00: 45: 15$ & $01: 39: 54$ & $01: 12: 15$ & $02: 27: 41$ & $00: 45: 54$ & 0 \\
\hline E & $02: 26: 56$ & $00: 46: 28$ & $01: 41: 56$ & $01: 33: 55$ & $02: 21: 42$ & $00: 45: 56$ & 0 \\
\hline F & $02: 17: 38$ & $00: 52: 29$ & $01: 39: 30$ & $01: 33: 42$ & $02: 08: 47$ & $00: 43: 51$ & 0 \\
\hline G & $02: 16: 23$ & $00: 46: 43$ & $01: 39: 22$ & $01: 31: 42$ & $02: 08: 55$ & $00: 44: 52$ & 0 \\
\hline
\end{tabular}

\section{Analisis Data Penugasan Karyawan di "Lia Fashion Komo Luar"}

Berdasarkan kelebihan biaya produksi pada tabel 3, maka langsung dianalisis dengan tahapan metode Hungarian yaitu:

1. Membentuk matriks efektifitas biaya (dalam satuan ribuan) menjadi:

$$
\left[\begin{array}{ccc}
2 & 3 & 25 \\
2 & 16 & 50 \\
3 & 2 & 8
\end{array}\right]
$$

2. Melakukan pengurangan baris dengan nilai terkecil setiap baris. Dengan demikian susunan biaya opportunity barisnya adalah:

$$
\left[\begin{array}{ccc}
0 & 1 & 23 \\
0 & 14 & 48 \\
1 & 0 & 6
\end{array}\right]
$$

3. Kemudian melakukan pengurangan kolom dengan nilai terkecil setiap kolom. Dengan demikian susunan nilai opportunity keseluruhannya adalah:

$$
\left[\begin{array}{ccc}
0 & 1 & 17 \\
0 & 14 & 42 \\
1 & 0 & 0
\end{array}\right]
$$

4. Membentuk penugasan optimum.

$$
\left[\begin{array}{c|cc}
0 & 1 & 17 \\
0 & 14 & 42 \\
1 & 0 & 0
\end{array}\right]
$$

Jumlah garis tidak sama dengan jumlah baris/kolom sehingga dilakukan revisi matriks.

5. Melakukan revisi sehingga susunan nilai opportunity yang baru adalah:

$$
\left[\begin{array}{ccc}
0 & 0 & 16 \\
0 & 13 & 41 \\
2 & 0 & 0
\end{array}\right]
$$

Kemudian dilakukan ulang langkah pembentukan optimasi sehingga diperoleh:

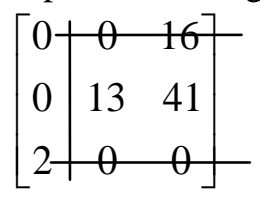


Jumlah garis telah sama dengan jumlah baris/kolom. Dengan demikian penyelesaian langkah optimasi telah tercapai susunannya yaitu karyawan A cocok untuk pekerjaan I dan II, karyawan B cocok untuk pekerjaan I, dan karyawan $\mathrm{C}$ cocok untuk pekerjaan II dan III.

6. Pembentukan penugasan

$$
\left[\begin{array}{ccc}
0 & 0(1) & 16 \\
0(1) & 13 & 41 \\
2 & 0 & 0(1)
\end{array}\right]
$$

7. Total kelebihan biaya produksi keseluruhan sebagai berikut:

\begin{tabular}{|c|l|l|}
\hline Karyawan & Jenis Pekerjaan Jahitan & $\begin{array}{l}\text { Biaya } \\
\text { Produksi }\end{array}$ \\
\hline A & Seragam Pramuka Putri & Rp 3.000 \\
\hline B & Seragam SMA Putri & Rp 2.000 \\
\hline C & Baju Pegawai & Rp 8.000 \\
\hline \multicolumn{2}{|l}{ Total Kelebihan Biaya Produksi } & Rp 11.000 \\
\hline
\end{tabular}

\section{Analisis Penugasan Karyawan di "Man Taylor"}

Berdasarkan waktu penugasan pada tabel 3 , maka langsung dianalisis dengan tahapan metode Hungarian mulai dari membentuk matriks efektifitas sampai diperoleh penugasan optimum sebagai berikut.

Matriks Penugasan Optimum

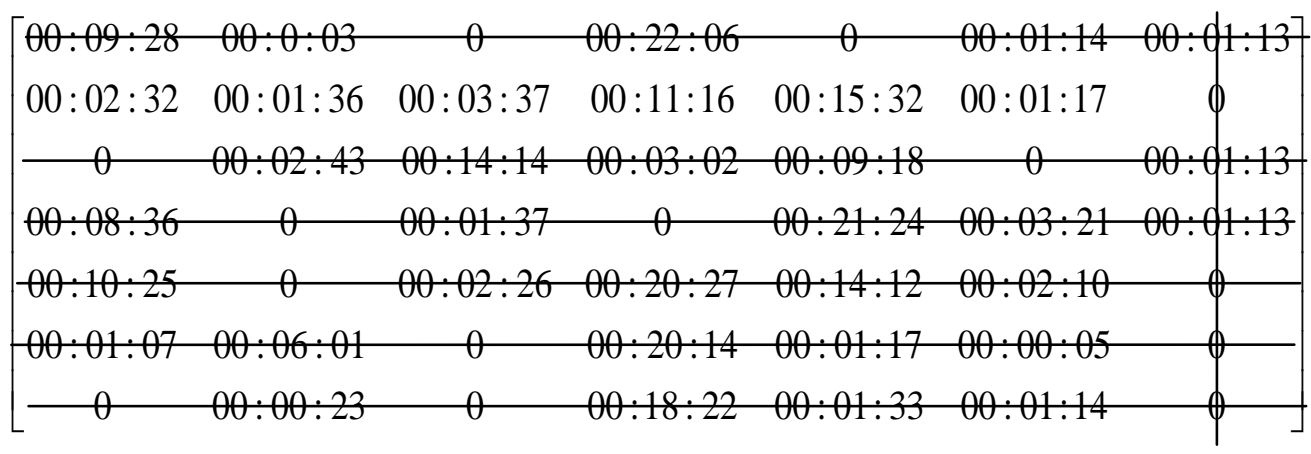

$\left[\begin{array}{ccccccc}00: 09: 28 & 00: 02: 03 & 0 & 00: 22: 06 & 0(1) & 00: 01: 14 & 00: 01: 13 \\ 00: 02: 32 & 00: 01: 36 & 00: 03: 37 & 00: 11: 16 & 00: 15: 32 & 00: 01: 17 & 0(1) \\ 0 & 00: 02: 43 & 00: 14: 14 & 00: 03: 02 & 00: 09: 18 & 0(1) & 00: 01: 13 \\ 00: 08: 36 & 0 & 00: 01: 37 & 0(1) & 00: 21: 24 & 00: 03: 21 & 00: 01: 13 \\ 00: 10: 25 & 0(1) & 00: 02: 26 & 00: 20: 27 & 00: 14: 12 & 00: 02: 10 & 0 \\ 00: 01: 07 & 00: 06: 01 & 0(1) & 00: 20: 14 & 00: 01: 17 & 00: 00: 05 & 0 \\ 0(1) & 00: 00: 23 & 0 & 00: 18: 22 & 00: 01: 33 & 00: 01: 14 & 0\end{array}\right]$

Berdasarkan matriks penugasan optimum kemudian diperoleh jumlah garis sama dengan jumlah baris/kolom. Dengan demikian penyelesaian langkah optimasi telah tercapai susunannya yaitu karyawan A cocok untuk menangani pekerjaan III \& IV, karyawan B cocok untuk menangani pekerjaan VII, karyawan C cocok untuk menangani pekerjaan I \& VI, karyawan D cocok untuk menangani pekerjaan II \& IV, karyawan E cocok untuk menangani pekerjaan II \& VII, karyawan $F$ cocok untuk menangani pekerjaan III \& VII, karyawan G cocok untuk menangani pekerjaan I \& III.
Selanjutnya dihitung total waktu penugasan optimal, sebagai berikut:

\begin{tabular}{|c|c|c|}
\hline Karyawan & $\begin{array}{c}\text { Jenis Pekerjaan } \\
\text { Jahitan }\end{array}$ & $\begin{array}{l}\text { Waktu } \\
\text { Produksi }\end{array}$ \\
\hline A & Kebaya & $02: 06: 17$ \\
\hline C & Rok kebaya & $00: 42: 43$ \\
\hline D & Celana panjang & $01: 12: 15$ \\
\hline E & Rok pendek & $00: 46: 28$ \\
\hline F & Baju PDH & $01: 39: 30$ \\
\hline G & Baju kemeja & $02: 16: 23$ \\
\hline Total Waktu Produksi & $08: 02: 56$ \\
\hline
\end{tabular}




\section{KESIMPULAN}

1. Sistem penugasan karyawan di "Lia Fashion Komo Luar" belum tepat. Sebaiknya penugasan karyawan yang tepat agar total kelebihan biaya produksi minimum yaitu karyawan A menjahit seragam pramuka putri, karyawan B menjahit seragam SMA putri, dan karyawan $\mathrm{C}$ ditugaskan menjahit baju pegawai.

2. Penugasan karyawan di "Man Taylor"belum tepat, yang tepat hanyalah karyawan A. Sebaiknya penugasan karyawan yang tepat agar waktu produksi minimum yaitu karyawan A menjahit baju kebaya, karyawan $\mathrm{C}$ menjahit rok kebaya, karyawan D menjahit celana panjang, karyawan E menjahit rok pendek, karyawan $\mathrm{F}$ menjahit baju $\mathrm{PDH}$, dan karyawan $\mathrm{G}$ menjahit baju kemeja.

\section{DAFTAR PUSTAKA}

Agustini, A.D dan Y. Rahmadi. 2004. Riset Operasional. PT Rineka Cipta, Jakarta.

Prawirosentono, S. 2005. Riset Operasi dan Ekonofisika. PT. Bumi Aksara, Jakarta.

Soemartojo, N. 1997. Program Linear. Depdikbud Direktorat Jenderal Pendidikan Dasar dan Menengah, Jakarta.

Taha, A.H. 1996. Riset Operasi Jilid I. Binarupa Aksara. Jakarta. 